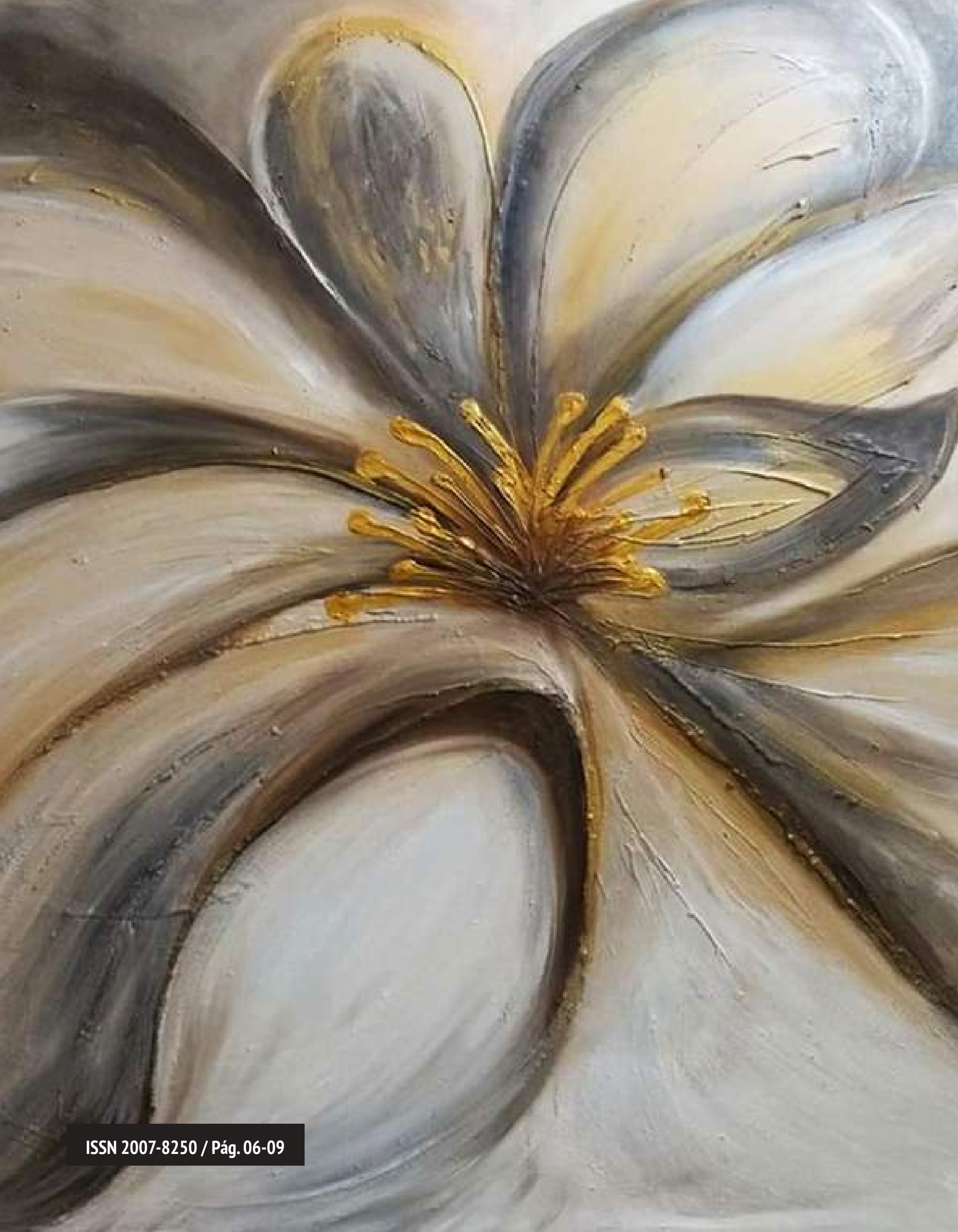




\section{REFLEXIONES ACERCA DE LA METODOLOGÍA DE LA ENSEÑANZA}

\section{Carlos Díaz Esparza}

No. 1 - Mayo 1990

Todo aquel que ha tenido experiencia en la enseñanza se ha encontrado con diversos problemas. ¿Qué hacer para lograr un mejor aprendizaje en los alumnos? ¿Cómo se les puede motivar? ¿Cómo despertar en ellos actitudes positivas hacia el estudio? ¿Qué método de enseñanza puede dar mejores resultados? ¿Qué técnica será la que convenga utilizar en la clase de la tarde? 
$\mathrm{E}$ xisten diversas respuestas a las interrogantes que surgen a diario en el ejercicio de la profesión docente. Lo que aquí se pretende es presentar una opción, en cuanto a la metodología de la enseñanza, que sirva de reflexión a quien busca nuevas o diferentes formas de enseñar.

Revisando la experiencia práctica de los docentes se puede encontrar que se implementan los más diversos métodos y técnicas educativas, sin embargo no siempre se logran las metas ni se obtiene la satisfacción de cumplir los objetivos planeados. De aquí surge la pregunta: ¿porqué no alcanzan los profesores sus propósitos? La respuesta más frecuente consiste en culpar a los alumnos por su falta de interés, capacidad, habilidades 0 su madurez. En parte puede esto resolver la interrogante, más no en su totalidad. Los alumnos culparán al profesor por su falta de disposición para dar el curso, su deficiente preparación, su escasa motivación, su interés por cumplir al programa independientemente de que ellos hayan aprendido, por la importancia que les da a los conocimientos memoristícos así como el sólo cumplir por la paga que recibe.

Se puede afirmar, además que sin lugar a duda hay un factor que desempeña un papel importante en esta problemática, el método de enseñanza. Con frecuencia los profesores se aferran a utilizar un sólo método en sus cursos. En ocasiones algunos utilizan varios pero tratando de que impliquen el menor esfuerzo de su parte y que no les lleve esto a trabajar más. El método es un recurso a través del cual el profesor puede alcanzar los objetivos que se proponga, pero

\section{Se implementan los más diversos métodos y técnicas educativas, sin embargo no siempre se logran las metas ni se obtiene la satisfacción de cumplir los objetivos planeados.}

bien, ¿qué objetivos serían estos? No es raro encontrarse con profesores que lo que pretenden es alcanzar sus objetivos personales, por ejemplo, tener un determinado número de alumnos reprobados. Tampoco es de extrañar que haya quienes pretenden que se cumplan con los contenidos del curso y nada más. Otros más se centran en lograr los objetivos del currículo. Pero, ¿cuántos hay que se interesan por los objetivos del alumno como persona?

A partir de lo anterior surge la pregunta que se interesa responder en estas líneas, ¿por qué no diseñar el método en función de los alumnos? Diseñar, no sólo elegir uno ya hecho. Esto puede sonar demasiado presuntuoso, no obstante es algo que se puede realizar, todo depende de los objetivos de enseñanza del profesor. Tampoco es tarea fácil, sobre todo si esto implica el tener que involucrar a los alumnos en la selección de los pasos a seguir, ya que es a ellos a quienes va a efectuar en su aprendizaje la decisión que se tome.

Un método idóneo, dentro de lo que cabe, para cada grupo de alumnos puede ser construído por el profesor. El paso inicial consiste en un DIAGNOSTICO en el que se considera al alumno y al maestro en función de sus características personales, tales como: intereses, habilidades, motivación, dificultades para aprender y para comunicarse, conocimientos previos, madurez para aceptar responsabilidades y cumplir con los compromisos contraídos, experiencia y disposición para bajar individualmente y en equipo.

Con los datos obtenidos y realizado el diagnóstico de fuerzas, debilidades, riesgos y oportunidades se propone entonces el planteamiento de las alternativas metodológicas a seguir en el curso.

Involucrar a los alumnos en la elección de la metodología del curso lleva a un mayor compromiso de su parte para el logro de sus objetivos de aprendizaje.

Hay ocasiones en las que a partir del diagnóstico realizado se tiene que implementar diferentes métodos para poder atender las necesidades del grupo. Habrá alumnos que prefieran una metodología directiva, otros elegirán una menos directa y algunos más una no directiva. ¿Puede hacerse un curso en que en vez de un grupo se tengan tres subgrupos y cada uno con su metodología? La respuesta es afirmativa. Ya ha sido realizado esto por el autor de estas notas. Si es po- 
sible lograr que el alumno alcance sus objetivos de aprendizaje sin que esto demerite el nivel y calidad del curso ni del currículo, por lo contrario lo enriquece.

El hecho de elegir la metodología al inicio del curso no obliga a continuar usándola tal cual (no es como en el matrimonio, "hasta la muerte"), ya que al ir avanzando en el curso se van presentando cambios por lo que se necesita hacer los ajustes que cada situación exija.

De manera similar conviene proceder con las técnicas de enseñanza. Cuando se planea una clase se elige la técnica que se piensa es la más conveniente para el tema, más al llegar al salón y encontrarse frente a los alumnos no siempre salen las cosas como se planearon. Por lo tanto, es recomendable hacer los ajustes que la situación precisa. Los grupos humanos no son estáticos, poseen su propia dinámica la cual se presenta cotidianamente, por lo que el profesor necesita estar atento a las condiciones que se presentan en cada clase, para con esto modificar sus estrategias y así lograr alcanzar los objetivos determinados.

Se puede comprar al profesor con un hábil "mariscal de campo" del futbol americano, éste tiene desarrollada la capacidad para ajustar la jugada elegida al momento de iniciar el conteo, si no lo hace así y mantiene la opción elegida inicialmente, sin considerar las condiciones del equipo contrario, incrementa las probabilidades de no lograr el avance deseado y además puede perder la posición que tenía su equipo en el terreno de juego antes de la jugada realizada.

También el profesor es como el entrenador del equipo, ya que es quien planea el juego y da las indicaciones durante él, es alguien con criterio flexible toma a tiempo las decisiones para modificar el plan original y así aumentar las probabilidades de ganar el partido.

Un entrenador rígido o temeroso, que no tiene alternativas o le provoca miedo cambiar el plan original, está determinado a no lograr las metas y los objetivos que se proponga.

El profesor flexible y valiente, interesado -como ya se dijo-en el aprendizaje de cada uno de sus alumnos, sabe ajustar sus planes y utilizar los métodos y técnicas que le garantizan un mejor resultado.

De lo anterior se puede desprender las siguientes ideas:
El profesor necesita estar atento a las condiciones que se presentan en cada clase, para con esto modificar sus estrategias y así lograr alcanzar los objetivos determinados.
1. El método es una herramienta que se utiliza a partir de un diagnóstico de la situación.

2. Si lo importante es el aprendizaje de los alumnos, conviene que ellos participen en la elección de los métodos y técnicas que se utilicen.

3. El cumplimiento de los objetivos se facilita, mayormente, si se hacen los cambios en los métodos y técnicas cuando el grupo y el maestro así lo requieren.

4. El profesor no trabaja para los contenidos, ni para el programa del curso, tampoco para el currículo, trabaja para los alumnos. Si se integran, alumnos y maestros, como un equipo de trabajo entonces se alcanzarán las metas del curso con mayor facilidad.

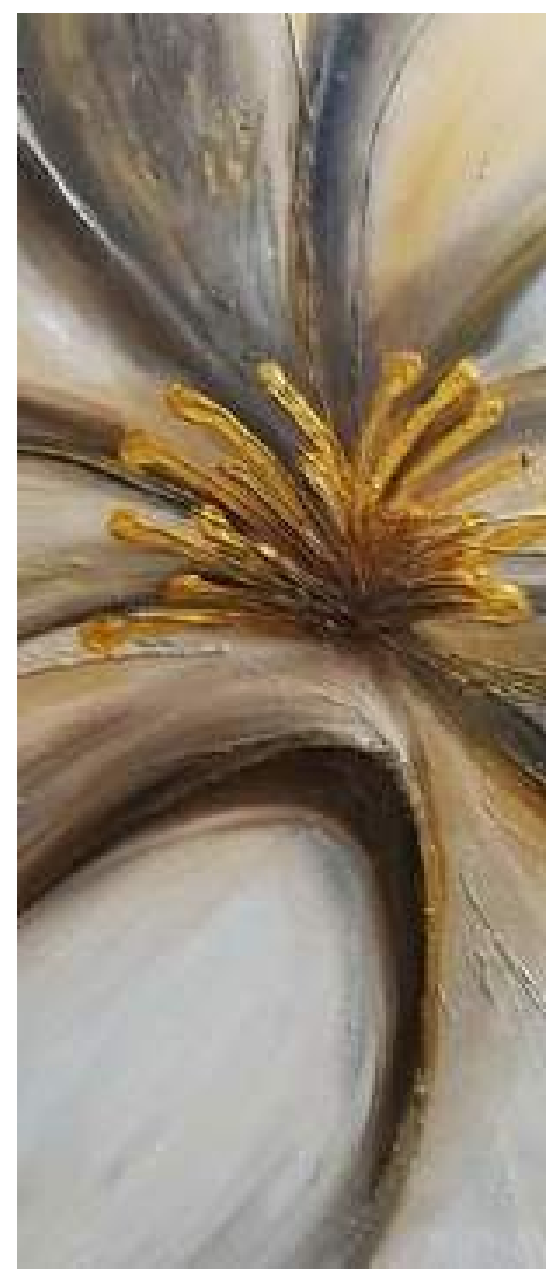

